Electromagnetic Biology and Medicine, 26: 63-72, 2007

DOI: 10.1080/15368370701205693

The original publication is available at www.informaworld.com

\title{
A Possible Effect of Electromagnetic Radiation from Mobile Phone Base Stations on the Number of Breeding House Sparrows (Passer domesticus)
}

\author{
JORIS EVERAERT AND DIRK BAUWENS \\ Research Institute for Nature and Forest, Brussels, Belgium
}

\begin{abstract}
A possible effect of long-term exposure to low-intensity electromagnetic radiation from mobile phone (GSM) base stations on the number of House Sparrows during the breeding season was studied in six residential districts in Belgium. We sampled 150 point locations within the 6 areas to examine small-scale geographic variation in the number of House Sparrow males and the strength of electromagnetic radiation from base stations. Spatial variation in the number of House Sparrow males was negatively and highly significantly related to the strength of electric fields from both the 900 and $1800 \mathrm{MHz}$ downlink frequency bands and from the sum of these bands $\left(\mathrm{Chi}^{2}\right.$-tests and AIC-criteria, $\left.\mathrm{P}<0.001\right)$. This negative relationship was highly similar within each of the six study areas, despite differences among areas in both the number of birds and radiation levels. Thus, our data show that fewer House Sparrow males were seen at locations with relatively high electric field strength values of GSM base stations and therefore support the notion that long-term exposure to higher levels of radiation negatively affects the abundance or behavior of House Sparrows in the wild.
\end{abstract}

Keywords Antenna; Bird; Electromagnetic radiation; GSM base station; Non thermal effect.

Address correspondence to Joris Everaert, Research Institute for Nature and Forest, Kliniekstraat 25, B-1070 Brussels, Belgium; E-mail: joris.everaert@ inbo.be 


\section{Introduction}

Mobile phones, also called cellular phones or handies, are now an integral part of modern life. The widespread use of mobile phones has been accompanied by the installation of an increasing number of base station antennas on masts and buildings. GSM base stations emit electromagnetic fields at high frequencies in the 900 and $1800 \mathrm{MHz}$ range (= downlink frequency bands), pulse modulated in low frequencies (Hyland, 2000). In recent years, increased public awareness and scientific research have questioned to what extent the non thermal exposure to low-intensity electromagnetic fields may affect the health, reproduction, well-being and behaviour of humans and other organisms. There is an active and, as yet, unsettled controversy about current safety standards. Some researchers and national committees advised more stringent safety standards, based on experimental data with reported biological effects from (chronic) non thermal exposures (Hyland, 2000; Belyaev, 2005a, b).

There are studies showing frequency-specific biological effects, and studies demonstrating that a high frequency signal modulated at certain low frequencies, or a signal that is pulsed, has more harmful effects than an unmodulated, steady carrier. These so-called 'window effects' greatly complicate any attempt to understand the relationship between electromagnetic radiation and health (Adey, 1981; Hyland, 2000; Lai, 2005; Belyaev, 2005a).

Public and scientific concern were also raised by results of some epidemiologic studies that examined the effects of long-term exposure on humans living near mobile phone base stations. A growing number of studies point to the existence of effects, ranging from changes in cognitive performance and sleep disturbances to serious illness and disablement, with even higher cancer rates (Santini et al., 2002; Navarro et al., 2003; Bortkiewicz et al., 2004; Eger et al., 2004; Wolf and Wolf, 2004; Hutter et al., 2006; Abdel-Rassoul et al., 2006).

Short-term laboratory experiments used mice, rats, chickens and other birds as study models to better understand the possible implications of electromagnetic fields on organismal functioning. In many studies however, 'mobile communication-like' signals were investigated that in fact were different from the real exposures in such aspects as intensity, carrier frequency, modulation, polarisation, duration and intermittence (Belyaev, 2005a, b; Lai, 2005).

Studies of the effects of exposure to electromagnetic fields on populations of wild birds can provide further insights into the potential impacts on animal and human health (Fernie and Reynolds, 2005). Birds are candidates for being good biological indicators for low-intensity electromagnetic radiation: they have thin skulls, their feathers can act as dielectric receptors of microwave radiation, many species use magnetic navigation, they are very mobile and possible psychosomatic effects are absent (Bigu-del-Blanco and Romero-Sierra, 1975; Balmori, 2005). Field studies of wild populations can also reveal possible effects of long-term exposure to radiation from GSM base stations. In addition, species like the House Sparrow (Passer domesticus) are especially of interest because a large proportion of the birds use higher breeding height locations like roof spaces (Wotton et al., 2002) where potentially higher levels of base station radiation are present.

Here we report results of a preliminary study that explored putative effects of electromagnetic radiation emitted by mobile phone base stations on the number of House Sparrows during the breeding season. Specifically, we examined small-scale geographic variation within each of six study areas in both the number of birds and the strength of electromagnetic radiation. If electromagnetic fields from GSM base stations have adverse effects on bird populations, this should result in a decreasing number of House Sparrows with increasing levels of radiation. 


\section{Materials and Methods}

\section{Data collection}

We determined, during the spring of 2006, the number of House Sparrow males and the strength of electromagnetic radiation from mobile phone (GSM) base stations at 150 locations that were distributed over six residential areas in the region of Gent - Sint-Niklaas (province of East Flanders, Belgium). The study areas were similar in overall appearance, with abundant hedges, bushes and other vegetation between the houses, and with one or more GSM base stations nearby.

The 150 study locations were selected in advance as points on a map (ArcGIS). All locations were situated along small roads within the residential areas and were at variable distances from the nearest GSM base station (mean $=352 \mathrm{~m}$, range $=91-903 \mathrm{~m}$, about $90 \%$ at $100-600 \mathrm{~m}$ ). The number of locations, and study dates, within each area were: Lokeren - Eksaarde $(\mathrm{N}=19$; April 9), Lokeren - Spoele ( $\mathrm{N}=27$, April 15), Lokeren - Bergendries ( $\mathrm{N}=17$, April 17), Sint Niklaas - Clementwijk ( $\mathrm{N}=25$, April 20), Gent- Wondelgem $(\mathrm{N}=38$, April 25) and Gent Mariakerke ( $\mathrm{N}=24$, April 26).

At each location, a point count of five minutes (see 'point transect count' in Bibby et al., 2000; Hustings et al., 1985) was made of the number House Sparrow males that were singing or otherwise visible within a distance of ca. $30 \mathrm{~m}$. Sightings of birds were done with binoculars (Swarovski EL 10x42). Counts were restricted to the morning hours (7-11h), when male House Sparrows are most active (Hustings et al., 1985; Van Dijk, 2004), on days with favourable weather conditions (no rain, little wind, sunny, normal temperatures).

Simultaneously, we measured the maximum value (peak hold) of the electric field strength (in $\mathrm{V} / \mathrm{m}$ ) from the downlink frequencies of GSM $900 \mathrm{MHz}(925-960 \mathrm{MHz})$ and GSM $1800 \mathrm{MHz}$ (1805-1880 MHz) base station antennas. Measurements at each location were made during two minutes for each frequency band. The electric field strength was measured using a portable calibrated high-frequency spectrum analyser (Aaronia Spectran HF-6080; typ. accuracy $\pm 3 \mathrm{~dB}$ ) with calibrated EMC directional antenna (HyperLOG 6080; logarithmic-periodic). To measure the maximum radiation values, the EMC antenna was turned around in all directions.

Additional antennas for the new UMTS-system are now being installed on several existing base stations in Belgium. Therefore, at several locations within each study area, the electric field strength from the downlink frequencies of UMTS antennas (2110-2170 MHz) was also checked, but no significant signals were found. Consequently, the UMTS variable was not taken into account for further analysis.

\section{Data analyses}

The sum (Egsm) of the measured GSM $900 \mathrm{MHz}($ Egsm900) and $1800 \mathrm{MHz}($ Egsm1800) electric field strength values was calculated using the formula: Egsm $=\sqrt{ }$ Egsm900² + Egsm1800² (Electronic Communications Committee, 2003). Prior to all analyses, the electric field strength variables were logarithmically transformed to achieve normality of their frequency distributions.

We explored relations between the number of House Sparrow males (dependent variable) and each of the three electric field strength variables. As the dependent variable consists of count data and is hence discontinuous, standard regression (or correlation) techniques are inappropriate. Instead, we used Poisson regressions (i.e., generalized linear models) with a log link function to examine putative relationships. Preliminary analyses indicated that significant variation among the six study areas was present for all variables (ANOVA, $\mathrm{P}<0.001$ ). Therefore we included "area" as a categorical factor in all models and considered it to be a proxy for all unknown, and 
hence unmeasured variables causing among area variation in the number of House Sparrows (e.g., habitat characteristics, food availability, temporal differences among censuses). Statistical analyses were done with S-PLUS v. 6.2.

\section{Results}

The number of House Sparrow males varied between zero and four at the different locations. The measured electric field strengths were seldom higher than $1 \mathrm{~V} / \mathrm{m}$, and most often well below that value (Table 1).

To explore the putative effects of area, electric field strength and their interaction on the number of House Sparrows, we performed separate analyses for each of the three radiation variables. As no significant interaction effect between area and electric field strength was detected in any of the three analyses ( $\mathrm{Chi}^{2}$-tests and AIC-criteria, $\left.\mathrm{P}>0.20\right)$, we excluded the interaction term from further treatments. The final regression models were highly similar for the three electric strength variables. They revealed significant variation among study areas $\left(\mathrm{Chi}^{2}{ }_{-}\right.$ tests, $\mathrm{P}<0.001$ ), and a highly significant negative effect of electric field strength on the number of House Sparrow males $\left(\mathrm{Chi}^{2}\right.$-tests and AIC-criteria, $\mathrm{P}<0.001$; Figure 1$)$. Estimates of the scaled deviance $(1.06-1.14)$ were very close to 1 , and examination of the regression residuals revealed no clear patterns or deviations from normality. These observations indicate an adequate fit of the models to the data.

\section{Table 1}

Summary statistics (mean, 95\% confidence interval, range) of the number of House Sparrow males and electric field strength variables in the six study areas. Means and confidence limits of the radiation variables were calculated after back-transformation of the logarithmically transformed data; the confidence intervals are therefore asymmetrical around the mean

\begin{tabular}{|c|c|c|c|c|c|}
\hline Study area & & $\begin{array}{c}\text { Number of } \\
\text { House Sparrow } \\
\text { males }\end{array}$ & $\begin{array}{c}E_{\mathrm{gsm} 900} \\
(\mathrm{~V} / \mathrm{m})\end{array}$ & $\begin{array}{c}\mathrm{E}_{\mathrm{gsm} 1800} \\
(\mathrm{~V} / \mathrm{m})\end{array}$ & $\begin{array}{c}E_{\mathrm{gsm}} \\
(\mathrm{V} / \mathrm{m})\end{array}$ \\
\hline \multirow[t]{3}{*}{ 1: Lokeren - Eksaarde } & mean & 1.5 & 0.153 & 0.075 & 0.193 \\
\hline & $95 \% \mathrm{CI}$ & $0.8-2.2$ & $0.108-0.216$ & $0.046-0.123$ & $0.139-0.270$ \\
\hline & Min - Max & $0-4$ & $0.036-0.494$ & $0.015-0.333$ & $0.052-0.505$ \\
\hline \multirow[t]{3}{*}{ 2: Lokeren - Spoele } & mean & 1.9 & 0.084 & 0.083 & 0.130 \\
\hline & $95 \% \mathrm{CI}$ & $1.5-2.3$ & $0.059-0.120$ & $0.058-0.120$ & $0.091-0.183$ \\
\hline & Min - Max & $0-4$ & $0.008-0.327$ & $0.013-0.394$ & $0.016-0.412$ \\
\hline \multirow[t]{3}{*}{ 3: Lokeren - Bergendries } & mean & 0.8 & 0.245 & 0.017 & 0.247 \\
\hline & $95 \% \mathrm{CI}$ & $0.3-1.3$ & $0.186-0.323$ & $0.009-0.031$ & $0.187-0.327$ \\
\hline & Min - Max & $0-3$ & $0.052-0.537$ & $0.004-0.125$ & $0.052-0.551$ \\
\hline \multirow[t]{3}{*}{ 4: Sint Niklaas - Clementwijk } & mean & 1.0 & 0.130 & 0.056 & 0.148 \\
\hline & $95 \% \mathrm{CI}$ & $0.6-1.4$ & $0.098-0.173$ & $0.039-0.082$ & $0.111-0.197$ \\
\hline & Min - Max & $0-3$ & $0.019-0.412$ & $0.009-0.231$ & $0.021-0.469$ \\
\hline \multirow[t]{3}{*}{ 5: Gent - Wondelgem } & mean & 1.3 & 0.109 & 0.040 & 0.121 \\
\hline & $95 \% \mathrm{CI}$ & $0.9-1.6$ & $0.079-0.151$ & $0.030-0.054$ & $0.089-0.165$ \\
\hline & Min - Max & $0-4$ & $0.016-1.006$ & $0.009-0.321$ & $0.022-1.056$ \\
\hline \multirow[t]{3}{*}{ 6: Gent - Mariakerke } & mean & 0.8 & 0.043 & 0.080 & 0.160 \\
\hline & $95 \% \mathrm{CI}$ & $0.3-1.2$ & $0.024-0.078$ & $0.049-0.130$ & $0.107-0.240$ \\
\hline & Min - Max & $0-4$ & $0.006-1.022$ & $0.017-0.824$ & $0.040-1.023$ \\
\hline
\end{tabular}




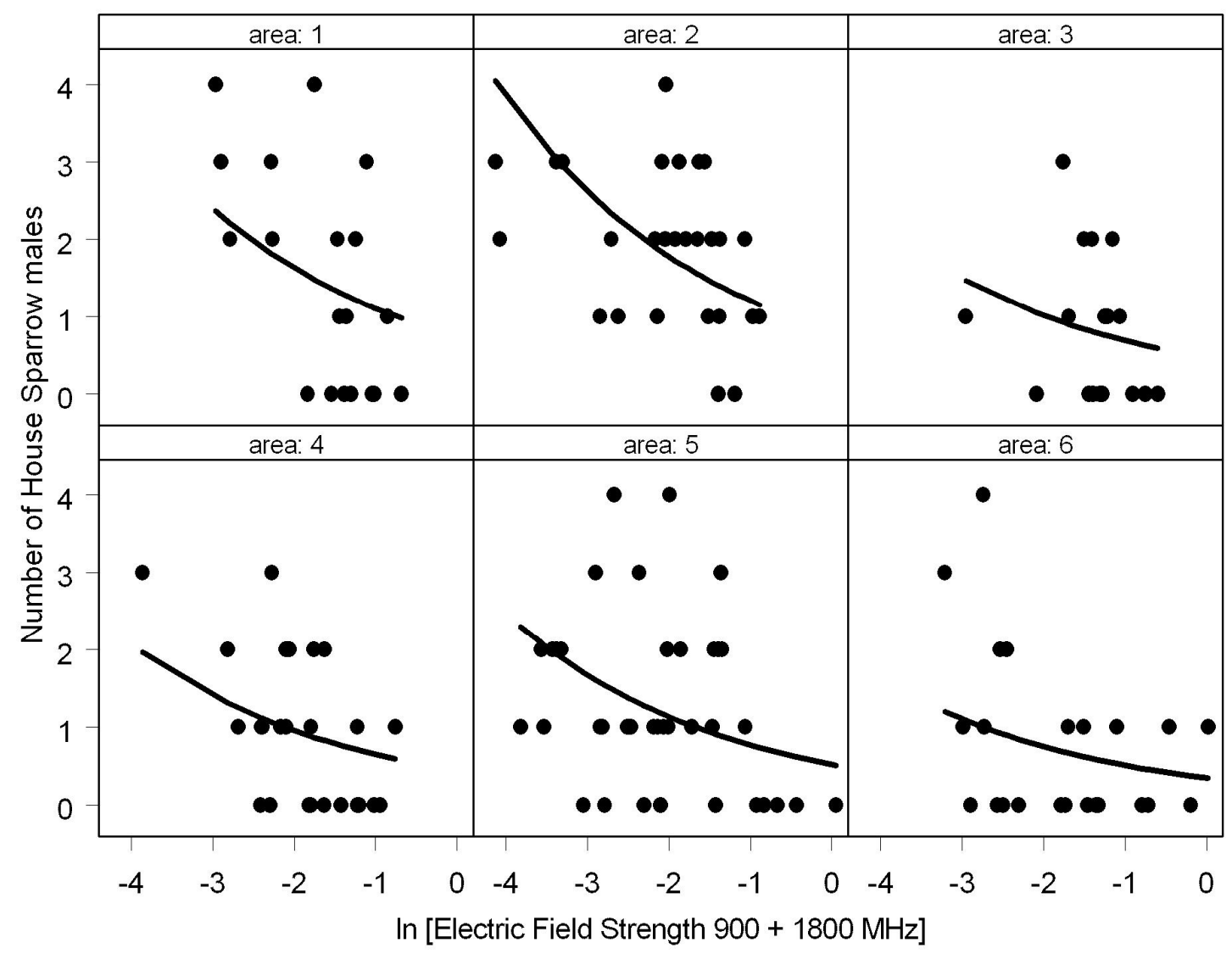

Figure 1. Scatterplots of the observed number of House Sparrow males as a function of the sum (Egsm) of GSM $900 \mathrm{MHz}$ and GSM $1800 \mathrm{MHz}$ electric field strength values (logarithmic scale) at the different locations within each of the six study areas. Regression lines were obtained by Poisson regressions and incorporated the effects of area and radiation intensity (see text).

We further explored the separate effects of electromagnetic radiation at the two frequencies by modelling the number of House Sparrow males as a function of area, electric field strength at 900 $\mathrm{MHz}$, electric field strength at $1800 \mathrm{MHz}$, and their interactions. The final model retained included highly significant effects of area and the two electric field strengths (Chi ${ }^{2}$-tests and AICcriteria, $\mathrm{P}<0.001$ ) and a marginally significant interaction effect between both field strengths $\left(\mathrm{Chi}^{2}\right.$-test, $\left.\mathrm{P}=0.02\right)$. This strongly suggests that the electromagnetic radiations at both frequencies have complex additive effects on the number of House Sparrow males.

Overall, analyses indicated that the strength of all three radiation variables decreased with increasing distance to the nearest base station (F-tests, $\mathrm{P}<0.001$ ). We therefore examined whether the negative relation between the number of birds and strength of radiation was induced by variation among sampling locations in the distance to GSM base stations. Upon adding distance to the nearest base station as an additional factor to the regression models that included area and electric field strength, distance did not account for a significant portion of the residual variation $\left(\mathrm{Chi}^{2}\right.$-tests and $\mathrm{AIC}$-criteria, $\left.\mathrm{P}>0.50\right)$. Conversely, when we forced distance as the first factor into the regression equations, both area and radiation strength were subsequently selected as highly significant factors $\left(\mathrm{Chi}^{2}\right.$-tests and AIC-criteria, $\left.\mathrm{P}<0.001\right)$. 


\section{Discussion}

Our results indicate that spatial variation among sampling locations in the number of House Sparrow males was negatively related to the strength of electric fields emitted by GSM base stations. Importantly, this relation was highly similar among the six study areas, as evidenced by the non-significant interaction effects between area and electric field strength, despite differences among areas in both the number of birds and radiation levels. Moreover, the negative association was detected for electric field strengths from both the 900 and $1800 \mathrm{MHz}$ frequency bands and from the sum of these frequency bands. Our analyses also revealed that the negative relation between the number of birds and strength of radiation was not a simple consequence of differences among sampling locations in distances to the nearest GSM base station. This can probably be attributed to variations in the orientation, position and number of antennas and to the shielding effects and multiple reflections from structures like buildings and trees, which affect local levels of exposure to electromagnetic radiation. Thus, our data show that fewer House Sparrow males were seen at locations with relatively high electric field strength values of GSM base stations and therefore support the notion that long-term exposure to higher levels of radiation negatively affects the abundance or behaviour of House Sparrows in the wild.

Nevertheless, our study should be considered as preliminary for several reasons. First, sampling locations were each visited only once, such that counts of the number of House Sparrow males and measurements of electric field strength are subject to some variation and estimation error. However, it is most likely that these errors are randomly distributed among locations. We also note that a single visit during the peak of the breeding season (April - May) is considered to be adequate to locate House Sparrow breeding territories (Hustings et al., 1985; Van Dijk, 2004). Second, because of the short study period, we ignore whether differences in bird counts reflect variation in abundance of breeding birds or in short-term behavioural responses like the tendency to sing. However, a decrease in singing intensity will result in a decrease of reproductive success and ultimately a decline of population size. Third, only the radiation from GSM base station antennas was measured. Probably, the distribution of possible other significant electromagnetic signals will be random, but due to the lack of measurements in other frequency bands (except for UMTS), this remains an object of further study. Fourth, as with all descriptive field studies, we cannot provide evidence for a causal relationship between radiation levels and the number of birds. Nevertheless, the fact that we found a highly similar pattern in each of the six study areas strengthens the possibility that the relationship is not a spurious one.

There are several unpublished and anecdotal reports about birds and mobile phone base stations, but we know of only one other published study that examined the effects of electromagnetic radiation from mobile phone base stations on wild bird populations. Balmori (2005) found a significantly lower number of White Stork (Ciconia ciconia) fledglings in nests exposed to relatively high electromagnetic radiation $(2.36 \pm 0.82 \mathrm{~V} / \mathrm{m})$ than in nests receiving lower levels of radiation $(0.53 \pm 0.82 \mathrm{~V} / \mathrm{m})$. Together with observations on aberrant behaviours of the adult birds, these results suggest that electromagnetic radiation interferes with reproduction in this wild population.

What could be the underlying mechanisms of the (putative) negative effects of radiation from GSM base stations on wild bird populations? Because all measured electric field strength values were far below what is required to produce heating as low as $0.5^{\circ} \mathrm{C}$ (i.e., $10 \mathrm{~mW} / \mathrm{cm}^{2}$ or ca. 194 $\mathrm{V} / \mathrm{m}$; Bernhardt, 1992), the effects should be considered as non thermal at very low intensities.

Non thermal effects of microwaves on birds were reported already 40 years ago (Tanner, 1966; Tanner et al., 1967). Most studies indicate that exposure of birds to electromagnetic fields 
generally changes, but not always consistently in effect or in direction, their behaviour, reproductive success, growth, development, physiology, endocrinology, and oxidative stress (Wasserman et al., 1984; Grigor'ev et al., 2003; Fernie and Reynolds, 2005). Of special relevance within the context of our research are laboratory studies that demonstrate negative effects of electromagnetic radiation from mobile phones on the development and survival of bird embryo's (Farrel et al., 1997; Youbicier-Simo and Bastide, 1999; Grigoriew, 2003).

Bird feathers are known to act as dielectric receptors of high frequency electromagnetic fields and some experiments indicate that audiofrequency pulse-modulated high frequency fields may induce piezoelectric effects in the feathers (Bigu-del-Blanco and Romero-Sierra, 1975a, b). These results are important in view of the fundamental role that feathers play in the life of birds and in the influence of environmental factors on bird behaviour. Experiments also indicated that microwave radiation can have the same averse effects on birds in flight as those observed in caged birds (Romero-Sierra et al., 1969).

Several bird species also use magnetic navigation (Liboff and Jenrow, 2000; Muheim et al., 2006) and can become disorientated when exposed to weak $(<1 / 50$ of geomagnetic field strength) high frequency magnetic fields (Ritz et al., 2004; Thalau et al., 2005). The available evidence concerning magnetoreception suggests that birds use a radical pair mechanism for a chemical compass, and a mechanism based on magnetite particles (Wiltschko and Wiltschko, 2005; Mouritsen and Ritz, 2005). Magnetite is an excellent absorber of microwave radiation at frequencies between 0.5 and $10.0 \mathrm{GHz}$ through the process of ferromagnetic resonance (Kirschvink, 1996), so that interaction with electromagnetic fields from mobile phone base stations might be possible.

In an experiment with Zebra Finches (Taenopygia guttata) that were temporary (10 minutes) stimulated with a pulsed electromagnetic field similar to the signal produced by mobile phones with carrier frequency $900 \mathrm{MHz}$, significant non thermal changes in the amount of neural activity by more than half of the brain cells were detected (Beasond and Semm, 2002). The effect did not appear tot be limited to magnetic sensory cells, but occurred in any part of the brain. The authors postulate that similar neural responses to different frequencies point toward a common mechanism of low frequency modulation, perhaps at the cell membrane. Such a stimulus might mimic a natural mechanism involved in cell communication. Although the peak electric field strength used in that experiment $\left(0.1 \mathrm{~mW} / \mathrm{cm}^{2}=\right.$ approx. $19 \mathrm{~V} / \mathrm{m}$; Beasond and Semm, 2002) was higher than the values measured in our study, results from other studies indicate that a long-term exposure at low intensities can produce the same effects as a short-term exposure at higher intensity (D'Andrea et al., 1986a, b; Lai, 2005; Belyaev, 2005a). This suggests that the non thermal effects of relatively weak electromagnetic radiation from mobile phone base stations can accumulate over time and have significant implications, as detected by several pilot epidemiological studies on humans (see Introduction).

Radiation from GSM base stations may also affect the local abundance of insects or other invertebrates and thereby indirectly influence the number of House Sparrows. Although adult House Sparrows are mainly seed-eaters, they need insects and other invertebrates to feed their young, such that it is likely that they will prefer areas with high abundance of invertebrates at the beginning of the breeding period. Several researchers have postulated that the lack of invertebrates might be an important factor in the reported decline of House Sparrow populations in urban areas (Wotton et al., 2002; Summers-Smith, 2003). Short-term exposure of pulsed mobile phone radiation with carrier frequency $900 \mathrm{MHz}$ resulted in a 50-60\% decrease of the reproductive capacity of insects (Panagopoulos et al., 2004). Similar results were also found with microwave radiation at other frequencies (Bol'shakov et al., 2001; Atli and Unlu, 2006). 
The results of our study suggest that long-term exposure to low-intensity (pulsed) electromagnetic radiation from GSM base stations may have significant effects on populations of wild birds. The exact mechanisms of these effects are as yet poorly understood. Given the potential importance that such effects may have on aspects of biodiversity and human health, more detailed studies in both the laboratory and the field are urgently needed to corroborate our results and to uncover the underpinning mechanistic relationships.

\section{References}

Abdel-Rassoul, G., Abou El-Fatech, O., Abou Salem, M., Michael, A., Farahat, F., ElBatanouny, M., Salem, E. (2006). Neurobehavioral effects among inhabitants around mobile phone base stations. Neurotoxicology. DOI: 10.1016/j.neuro.2006.07.012.

Adey, W.R. (1981). Tissue interactions with non-ionizing electromagnetic fields. Physiol. Rev. 61:435-514.

Atli, E., Unlu, H. (2006). The effects of microwave frequency electromagnetic fields on the development of Drosophila melanogaster. Int. J. Radiat. Biol. 82:435-441.

Balmori, A. (2005). Possible effects of electromagnetic fields from phone masts on a population of White Stork (Ciconia ciconia). Electromagn. Biol. Med. 24:109-119.

Beasond, R.C., Semm, P. (2002). Responses of neurons to an amplitude modulated microwave stimulas. Neurosci. Lett. 333:175-178.

Belyaev, I.Y. (2005a). Non-thermal Biological Effects of Microwaves. Microwave Review 11:1329.

Belyaev, I.Y. (2005b). Nonthermal Biological Effects of Microwaves: Current Knowledge, Further Perspective, and Urgent Needs. Electromagn. Biol. Med. 24:375-403.

Bernhardt, J.H. (1992). Non-ionizing radiation safety: radiofrequency radiation, electric and magnetic fields. Phys. Med. Biol. 37:80-84.

Bibby, C.J., Burgess, N.D., Hill, D.A., Mustoe, S.H. (2000): Bird Census Techniques. London: Academic Press.

Bigu-del-Blanco, J., Romero-Sierra, C. (1975a). The properties of bird feathers as converse piezoelectric transducers and as receptors of microwave radiation. I. Bird feathers as converse piezoelectric transducers. Biotelemetry 2:341-353.

Bigu-del-Blanco, J., Romero-Sierra, C. (1975b). The properties of bird feathers as converse piezoelectric transducers and as receptors of microwave radiation. II. Bird feathers as dielectric receptors of microwave radiation. Biotelemetry 2:354-364.

Bol'shakov, M.A., Kniazeva, I.R., Lindt, T.A., Evdokimov, E.V. (2001). Effect of low-frequency pulse-modulated $460 \mathrm{MHz}$ electromagnetic irradiation on Drosophila embryos (article in Russian). Radiats. Biol. Radioecol. 41:399-402.

Bortkiewicz, A., Zmyslony, M., Szyjkowska, A., Gadzicka, E. (2004). Subjective symptoms reported by people living in the vicinity of cellular phone base stations. Med. Pr. 55:345351.

D'Andrea, J.A., DeWitt, J.R., Emmerson, R.Y., Bailey, C., Stensaas, S., Gandhi, O.P. (1986a). Intermittent exposure of rats to $2450 \mathrm{MHz}$ microwaves at $2.5 \mathrm{~mW} / \mathrm{cm}^{2}$ : behavioral and physiological effects. Bioelectromagnetics 7:315-328.

D’Andrea, J.A., DeWitt, J.R., Gandhi, O.P., Stensaas, S., Lords, J.L., Nielson, H.C. (1986b). Behavioral and physiological effects of chronic $2450 \mathrm{MHz}$ microwave irradiation of the rat at $0.5 \mathrm{~mW} / \mathrm{cm}^{2}$. Bioelectromagnetics 7:45-56. 
Eger, H., Hagen, K.U., Lucas, B., Vogel, P., Voit, H. (2004). Influence of the spatial proximity of mobile phone base stations on cancer rates (article in German). Umwelt-MedizinGesellschaft 17:273-356.

Electronic Communications Committee (2003): Measuring non-ionising electromagnetic radiation $(9 \mathrm{kHz}-300 \mathrm{GHz})$. Recommendation adopted by the Working Group "Frequency Management" (FM). Electronic Communications Committee (ECC) within the European Conference of Postal and Telecommunications Administrations (CEPT). ECC/REC/(02)04.

Farrel, J.M., Litovitz, T.L., Penafiel, M. (1997). The effect of pulsed and sinusoidal magnetic fields on the morphology of developing chick embryos. Bioelectromagnetics 18:431-438.

Fernie, K.J., Reynolds, S.J. (2005). The effects of electromagnetic fields from power lines on avian reproductive biology and physiology: a review. J. Toxicol. Environ. Health B Crit. Rev. 8:127-140.

Grigor'ev, O.A., Bicheldei, E.P., Merkulo, A.V. (2003). Anthropogenic EMF effects on the condition and function of natural ecosystems (article in Russian). Radiats. Biol. Radioecol 43:544-551.

Grigoriew, J.G. (2003). The influence of electromagnetic fields from mobile phones on chicken embyo's (article in German). Journal für Strahlungs-Biologie 5:541-544.

Hustings, F., Kwak, R., Opdam, P., Reijnen, M. (1985): Manual bird census work: techniques. backgrounds, guidelines and reporting. Nature conservation in the Netherlands, vol. III (publication in Dutch). Zeist: Pudoc, Wageningen \& Nederlandse Vereniging tot Bescherming van Vogels.

Hutter, H.P., Moshammer, H., Wallner, P., Kundi, M. (2006). Subjective symptoms, sleeping problems, and cognitive performance in subjects living near mobile phone base stations. Occup. Environ. Med. 63:307-313

Hyland, G.J. (2000). Physics and biology of mobile telephony. The Lancet 356:1833-1836.

Kirschvink, J.L. (1996). Microwave absorption by magnetite: a possible mechanism for coupling nonthermal levels of radiation to biological systems. Bioelectromagnetics 17:187-194.

Lai, H. (2005). Biological effects of radiofrequency electromagnetic field. Encyclopedia of Biomaterials and Biomedical Engineering. DOI: 10.1081/E-EBBE-120041846.

Liboff, A.R., Jenrow, K.A. (2000). New model for the avian magnetic compass. Bioelectromagnetics 21:555-565.

Mouritsen, H., Ritz, T. (2005). Magnetoreception and its use in bird navigation. Curr. Opin. Neurobiol. 15:406-414.

Muheim, R., Moore, F.R., Phillips, J.B. (2006). Calibration of magnetic and celestial compass cues in migratory birds - a review of cue-conflict experiments. J. Exp. Biol. 209:2-17.

Navarro, E.A., Segura, J., Portolés, M., Gómez-Perretta de Mateo, C. (2003). The Microwave Syndrome: A Preliminary Study in Spain. Electromagn. Biol. Med. 22:161-169.

Panagopoulos, D.J., Karabarbounis, A., Margaritis, L.H. (2004). Effect of GSM 900-MHz mobile phone radiation on the reproductive capacity of Drosophila melanogaster. Electromagn. Biol. Med. 23:29-43.

Ritz, T., Thalau, P., Phillips, J.B., Wiltschko, R., Wiltschko, W. (2004). Resonance effects indicate radical pair mechanism for avian magnetic compass. Nature 429:177-180.

Romero-Sierra, C., Husband, C., Tanner, J.A. (1969): Effects of microwave radiation on Parakeets in flight. Ottowa: Control Systems Laboratory.

Santini, R., Santini, P., Danze, J.M., Le Ruz, P., Seigne, M. (2002). Study of the health of people living in the vicinity of mobile phone base stations: I. Influences of distance and sex. Pathol. Biol. 50:369-373. 
Summers-Smith, J.D. (2003). The decline of the House Sparrow: a review. Brit. Birds 96:439446.

Tanner, J.A. (1966). Effect of microwave radiation on birds. Nature 210:636.

Tanner, J.A., Romero-Sierra, C., Davie, S.J. (1967). Non-thermal effects of microwave radiation on birds. Nature 216:1139.

Thalau, P., Ritz, T., Stapput, K., Wiltschko, R., Wiltschko, W. (2005). Magnetic compass orientation of migratory birds in the presence of a $1.315 \mathrm{MHz}$ oscillating field. Naturwissenschaften 92:86-90.

Van Dijk, A.J. (2004): Manual for the breeding-bird monitoring project (publication in Dutch). Beek-Ubbergen: SOVON Vogelonderzoek Nederland.

Wasserman, F.E., Dowd, C., Schlinger, B.A., Byman, D., Battista, S.P., Kunz, T.H. (1984). The effects of microwave radiation on avian dominance behavior. Bioelectromagnetics 5:331339.

Wiltschko, W., Wiltschko, R. (2005). Magnetic orientation and magnetoreception in birds and other animals. J. Comp. Physiol. A Neuroethol. Sens. Neural. Behav. Physiol. 191:675-693.

Wolf, R., Wolf, D. (2004). Increased incidence of cancer near a cellphone transmitter station. Int. J. Cancer Prev. 1:123-128

Wotton, S.R., Field, R., Langston, R.H.W., Gibbons, D.W. (2002). Homes for birds: the use of houses for nesting by birds in the UK. Brit. Birds 95:586-592.

Youbicier-Simo, B.J., Bastide, M. (1999). Pathological effects induced by embryonic and postnatal exposure to EMFs radiation by cellular mobile phones. Radiat. Protect. 1:218-223. 